\title{
Literatur
}

1. Helfrich, B. und G. Sparmberg, Hoppe-Seyler's Z. physiol. Chem. 221, 92 (1933). - 2. Fishman, W. H., in: Sumner J. B. und K. Mrrbäck, The Enzyms, Bd. I/1. Academic Press Inc. Publ., New York (1950). - 3. Fishman, W. H., J. biol. Chemistry 131, 225 (1939). - 4. Nnmo-Smith, R. H., Biochim. biophysica Acta (Amsterdam) 50, 166 (1961). - 5. SPENCER, B. und R. T. WilliIAMS, Biochem. J. 48, 537 (1951). - 6. Abur-Fadr, M. A. M. J. Clin. Path., London 10,387 (1957). - 7. Bernfeld, P. und W. H. Fishiman, Science (New York) 112, 653 (1950).-8. NAYYAR, S.N. und D. GuICK, J. biol. Chemistry 222, 73 (1956). - 9. SMrrH, E. E. B. und G. T. MrLls, Biochem. J. 52, 464 (1952). - 10. Levvy, G. A., A. J. Hay und C.A.MarSH, Biochem. J. 65, 203 (1957). - 11. LEvvy, G.A. und C. A. MARSH, Nature (London) 180, 197 (1957). - 12. DohrMANN, R. und H. J. UhLes, Klin. Wschr. 41, 527 (1963). - 13. WALKER, P. G. und G. A. LeVVY, Biochem. J. 54, 56 (1953). 14. Robinson, D., J. N. Smith und R. T. Williams, Biochem. J. 53, 125 (1953). - 15. Billett, F., Biochem. J. 57, 159 (1954). - 16. Brahm, C., Hoppe-Seyler's Z. physiol. Chem. 28, 439 (1899). 17. Fischer, E., Anleitung zur Darstellung organischer Präparate,
9. Aufl., Verlag Friedrich Vieweg und Sohn, Braunschweig (1920). - 18. Dohrmann, R. und R. KLespre, Klin. Wschr. 38, 595 (1960). - 19. Dohrmann, R., Zschr. exper. Med. 132, 585 (1960). - 20. Dohrmann, R., Habil.-Schrift, Bonn (1961). 21. Goldbarg, J. A., E. P. Pineda, B. M. Banks und A. M. Rutendurg, Gastroenterology, Baltimore 36, 192 (1959). - 22. Hackensellner, H. A., F. Seelich und H. Lind, Wien. klin. Wschr. 70, 28 (1958). - 23. Talalay, P., W. H. Fishman und C. Huggn, J. biol. Chemistry 166, 757 (1946). - 24. DohrmanN, R., Dtsch. Arch. klin. Med. 206, 322 (1960). - 25. Fishman, W. H., B. SPRINGRR und R. BRUNitit, J. biol. Chemistry 173, 449 (1948). - 26. Di Somma, A. A., J. biol. Chemistry 133, 277 (1940). — 27. Goldstein, G., Clin. Chem. (New York) 7, 136 (1961). - 28. Plaice, C. H. J., J. Clin. Path., London 14, 661 (1961). - 29. KerR, L. M. H., A. F. GraHAM und G. A. Levvy, Biochem. J. 42, 191 (1948). - 30. Methressel, J. und R. Nirrus, Acta biol. med. german. 13, 411 (1964). - 31. Nirrus, R., Inaug.-Diss., Halle (1961).
Dr. med. R. Nilius

I. Med. Klinik der Universität Halle-Wittenberg

X 402 Halle/Saale, Leninallee 22

\section{Die Bestimmung der Triglyceride im Serum mit der Hantzsch-Reaktion}

\author{
Von F. Dunsbach \\ Aus dem Chemisch-Physiologischen Institut des Allgemeinen Krankenhauses St. Georg, Hamburg \\ (Leiter: Dr.pbil. F. Fretwurst)
}

(Eingegangen am 26. November 1965)

\begin{abstract}
Es wird eine Methode zur Bestimmung der Triglyceride im Blutserum mit Hilfe der Hantzscb-Reaktion beschrieben. Nach adsorptiver Abtrennung der übrigen glycerinhaltigen Lipidfraktionen wird das durch Verseifung der Triglyceride erhaltene Glycerin mit Perjodat zu Formaldehyd oxydiert und der entstandene Formaldehyd mit Acetylaceton und Ammoniumsalz in essigsaurer Lösung zu Diacetyldihydrolutidin umgesetzt. Die gelbgefärbte amylalkoholische Lösung wird bei $400-420 \mathrm{~m} \mu$ photometriert.

A method is described for the determination of triglycerides in blood serum with the aid of the Hantzsch reaction. After removal of the remaining glycerol-containing lipid fractions by adsorption, the glycerol obtained by saponification of the triglycerides is oxidised to formaldehyde with periodate and the resulting formaldehyde converted into diacetyldihydrolutidine with acetyl acetone and ammonium salt in acetic acid solution. The yellow amyl alcoholic solution is quantised photometrically at $400-420 \mathrm{~m} \mu$.
\end{abstract}

Die steigende Bedeutung der Erfassung von Lipoidstoffwechselstörungen durch biochemische Methoden führte in den letzten Jahren zu einer Reihe von Veröffentlichungen über die Bestimmung der Triglyceride im Blutserum und Blutplasma. Dabei sind bis heute drei in ihren Grundzügen verschiedene Methoden bekannt geworden. So bestimmten vAN HANDEL und ZILVERSMIT (1) die Triglyceride nach Abtrennung der übrigen glycerinhaltigen Serumlipide (Adsorption an „Doucil") durch Verseifung mit alkoholischer Kalilauge, Oxydation des entstandenen Glycerins mit Perjodat zu. Formaldehyd und Umsetzung des Formaldehyds mit Chromotropsäure nach LAmberT und NeIsh (2). Mendelson und Antonis (3) bedienten sich zur Bestimmung des freigesetzten Glycerins der Skraup'schen Chinolinsynthese, bei der Glycerin mit o-Aminophenol in Schwefelsäure bei Anwesenheit eines Oxydations- mittels zu 8-Oxychinolin umgesetzt wird, dessen Magnesiumsalz fluorimetrisch gemessen wird. EGGSTEIN und KREUTTZ (4) beschrieben eine direkte enzymatische Methode zur Bestimmung der Triglyceride, die auf der Bildung von $\alpha$-Glycerophosphat aus dem durch Verseifung freigesetżten Glycerin und ATP bei Anwesenheit von Glycerokinase beruht.

Die hier beschriebene Methode lehnt sich insofern an die von VAN HANDEL und ZILVERSMit an, als auch hier die Trennung der Triglyceride von den übrigen glycerinhaltigen Bestandteilen mit Hilfe eines Adsorbens, Verseifen der Triglyceride zu Glycerin und Fettsäuren und Oxydation des Glycerins mit Perjodat zu Formaldehyd erfolgt. Zur Bestimmung des Formaldehyds dient die Reaktion nach HANIZSCH (5). Diese Reaktion wurde von Nasf (6) zur Bestimmung des Formaldehyds beschrieben und beruht darauf, daß Formaldehyd mit Acetyl- 
aceton und Ammoniak in schwach essigsaurer Lösung zu Diacetyldihydrolutidin reagiert:

$$
2 \mathrm{CH}_{3}-\mathrm{CO}-\mathrm{CH}_{2}-\mathrm{CO}-\mathrm{CH}_{3}+\mathrm{HCHO}+\mathrm{NH}_{3}=
$$

Methodik

Reagenzien

Chloroform, redest.

Kieselgel ( $\mathrm{Fa}$. Merck, 0,05-0,2 mm): $4 \mathrm{Stdn}$. bei $120^{\circ}$ trocknen und in einer gut verschlossenen Flasche aufbewahren.

Alkobolische Kalilauge: Stammlösung: $2 \mathrm{~g} \mathrm{KOH}$ p.a. werden in $100 \mathrm{ml}$ 96-proz. reinem Alkohol gelöst; Gebrauchslösung: $10 \mathrm{ml}$ Stammlösung werden mit 96-proz. reinem Alkohol ad $50 \mathrm{ml}$ verdünnt; diese Lösung ist täglich frisch anzusetzen!

Essigsäure: 2-proz. $\nabla / \mathrm{v}$.

Natrizmmetaperjodat $(0,05 \mathrm{M}): 1,07 \mathrm{~g} \mathrm{NaJO}_{4}$ werden in dest. Wasser ad $100 \mathrm{ml}$ gelöst.

Natriumarsenit $(0,5 \mathrm{M}): 2,25 \mathrm{~g} \mathrm{NaOH}$ p.a. werden in einem $100 \mathrm{ml}$ Meßkolben in etwa $50 \mathrm{~m} /$ dest. Wasser gelöst. Nach Abkühlen gibt man $5 \mathrm{~g} \mathrm{As}_{2} \mathrm{O}_{3}$ p.a. zu und füllt nach dem Lösen mit dest. Wasser zur Marke auf.

Acetylacetonreagenz: In einen $1 / \mathrm{Me} ß k$ kolben gibt man etwa $300 \mathrm{~m} /$ dest. Wasser, dazu $130 \mathrm{~m} / 25$-proz. Ammoniak; dann gießt man unter Kühlen $125 \mathrm{~m} l$ Eisessig zu und füllt nach Zusatz von $2 \mathrm{~m} l$ Acetylaceton mit dest. Wasser zur Marke auf. Nach kurzem Mischen ist die Lösung klar und gebrauchsfertig. In brauner Flasche aufbewahrt ist sie bei Zimmertemperatur mehrere Monate haltbar.

Isoamylalkobol, reinst

Natriumsulfat: $\mathrm{Na}_{2} \mathrm{SO}_{4}$ p.a. 4 Stdn. bei etwa $300^{\circ}$ trocknen und in einer gut schließenden Flasche aufbewahren.

\section{Arbeitsvorschrift}

Alle zur Bestimmung verwendeten Glasgeräte werden mit Alkohol gut gereinigt.

In ein $170 \times 30 \mathrm{~mm}$ Glas mit Schliffstopfen (NS 29) wird $1 \mathrm{ml}$ Serum gegeben. Dazu pipetticrt man $20 \mathrm{ml}$ Chloroform, setzt $4 \mathrm{~g}$ Kieselgel zu und schüuttelt nach Verschließen des Glases kräftig, um eine möglichst feine Verteilung der ausgefällten Eiweißkörper zu erreichen. Man läßt die Mischung 30 Minuten stehen und schüttelt während dieser Zeit noch $6 \mathrm{mal}$ je 1 Minute. Es empfiehlt sich, statt dessen in einer Schüttelmaschine 10-15 Min. zu schütteln. Anschließend filtriert man durch ein $11 \mathrm{~cm}$ Faltenfilter, pipettiert $2 \mathrm{ml}$ des klaren Filtrats in ein Reagenzglas und dampft das Chloroform bei $80^{\circ} \mathrm{im}$ Wasserbad ab. Wat das Serum stark trübe, was einen hohen Triglyceridwiert erwarten läßt, so werden nur 1 bzw. $0,5 \mathrm{~m} l$ Filtrat eingedampft. $\mathrm{Zu}$ dem trockènen Rückstand gibt man $0,5 \mathrm{ml}$ alkoholische Kalilauge und verseift $30 \mathrm{Min}$. in einem Wasserbad von $60^{\circ}$. Anschließend kühlt man unter fließendem Wasser ab und säuert mit 0,5 $\mathrm{m} / 2$-proz. Essigsäure an. Dabei trübt sich die Lösung durch ausfallende freie Fettsäuren und Cholesterin. An dieser Stelle wird der Leerversuch angesetzt, indem man $0,5 \mathrm{ml}$ 96-proz. Alkohol mit 0,5 ml 2-proz. Essigsäure vermischt.

Zum Versuch und Leerversuch gibt man je $0,1 \mathrm{~m} /$ Natriummetaperjodatlösg. und läßt nach gutem Durchmischen 10 Min. stehen; danach wird die Reaktion durch Zugabe von $0,1 \mathrm{ml}$ Natriumarsenitlsg. abgestoppt. Nach Zugabe von $2,5 \mathrm{ml}$ Acetylacẹtonreagenz werden die Röhrchen $20 \mathrm{Min}$. in ein Wasserbad von $60^{\circ}$ gestellt. Nach Abküblen und Zugabe von $6 \mathrm{ml}$ Amylalkohol wird etwa 5-10 Sekunden kräftig geschüttelt; dabei geht der gebildete Farbstoff quantitativ in die Amylalkoholphase über. Die Mischung wird in ein Zentrifugenglas gegossen und 5 Min. bei etwa 3000 U./Min. zentrifugiert. Von der überstehenden amylalkoholischen Lösung werden etwa $5 \mathrm{~m} /$ in ein weiteres Zentrifugenglas pipettiert, eine Spatelspitze (etwa 0,5-0,8 g) Natriumsulfat zugesetzt und nach kurzem Schütteln ein zweites Mal zentrifugiert. Die Extinktion der überstehenden klaren Lösung wird in $1 \mathrm{~cm}$ Schichtdicke zwischen 400 und $420 \mathrm{~m} \mu$ gemessen (Maximum bei $410 \mathrm{~m} \mu$ ). Die Farbe ist, vor direktem Sonnenlicht geschützt, mindestens eine Stunde beständig. Wenn nicht sofort abgelesen werden kann, bewahrt man die Probe am besten im Dunkeln auf.

Die Berechnung des Triglyceridgehaltes aus den Extinktionen erfolgt mit Hilfe eines Faktors F, den man aus einer Eichkurve bestimmt. Die Berechnung lautet dann:

$$
\text { (Evers. } \left.-E_{\text {Leervers. }}\right) \cdot \mathrm{F}=\mathrm{mg} \% \text { Triglyceride }
$$

Aufstellung der Eichkurve: Aus einer $500 \mathrm{mg} \%$ Lösung von Maisöl in Chloroform wird folgende Verdünnungsreihe angesetzt:

$$
\begin{array}{lllll}
1: 50 & 2: 50 & 3: 50 & 4: 50 & 5: 50
\end{array}
$$

entspr.: $100200 \quad 300400500 \mathrm{mg}$ Triglyceride $/ 100 \mathrm{ml}$ Serum.

$2 \mathrm{~m} l$ einer jeden Verdünnung werden in ein Reagenzglas pipettiert und wie beim Versuch beschrieben weiterverarbeitet. Die nach Abzug des Leerwertes erhaltenen Extinktionen $E$ werden in ein Koordinatensystem als Ordinate gegen die Konzentration in $\mathrm{mg} \%$ als Abszisse eingetragen. An einer beliebigen Stelle der erbaltenen Geraden errechnet man den Faktor: $F=\frac{\mathrm{mg} \%}{\mathrm{E}}$.

\section{Ergebnisse und Diskussion}

Zur Trennung der Triglyceride von den übrigen glycerinhaltigen Bestandteilen des Serums wurden Kieselgel $(3,7,8)$ und „Doucil“ (1) vorgeschlagen. Deshalb wurden Kieselgel (Merck 0,05-0,2 mm) und „Doucil“" miteinander verglichen. Die Abweichungen zwischen beiden Adsorptionsmitteln lagen innerhalb des mittleren Fehlers der Methode. Die Verseifung konnte ebenso wie die Oxydation der Methode von vaN HANDEL und ZiLVERSMIT entnommen werden. Allerdings erübrigt sich das Entfernen des Alkohols nach dem Verseifen, da die Folgereaktionen durch Äthanol nicht gestört werden. Das Ansäuern der verseiften Probe muß durch Essigsäure erfolgen, um den für die Hantzsch-Reaktion günstigen pH-Bereich zu gewährleisten. Die Umsetzung des Formaldehyds mit Acetylaceton zu Diacetyldihydrolutidin ist unter den oben angegebenen Bedingungen nach 10 Minuten bereits quantitativ. Längeres Erwärmen bis zu einer Stunde brachte keine Änderung der Extinktionswerte. Die Extinktionskurve der rein wäßrigen und der amylalkoholischen Lösung weichen voneinander $\mathrm{ab}(\mathrm{Abb} .1)$. Deshalb muß der amylalkoholischen

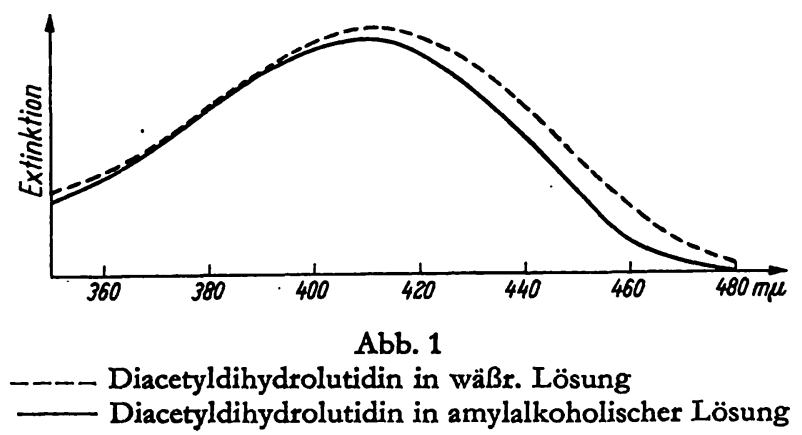


Lösung zur Entfernung des Wassers Natriumsulfat zugesetzt werden. Der Zusatz von Natriumsulfat verhindert außerdem eine Trübung der Lösung durch ausfallendes Wasser, die leicht eintritt, wenn nicht sofort abgelesen wird (größere Serien) oder wenn Temperaturschwankungen auftreten.

Die Eichkurve (Abb. 2) zeigt, daß das Lambert-Beer'sche Gesetz bis zu einer Konzentration von etwa $700 \mathrm{mg} \%$ gilt. Höhere Konzentrationen zeigen sich durch starke Trübung des Serums an, so daß man durch Einsetzen von $1 \mathrm{ml}$ bzw. $0,5 \mathrm{~m} l$ der nach Adsorption erhaltenen Chloroformlösung den gesamten möglichen Bereich erfassen kann. Triglyceridwerte über $1000 \mathrm{mg} \%$ sind selten; bei 500 Untersuchungen fanden wir nur 7 Fälle (maximal $2100 \mathrm{mg} \%$ ).

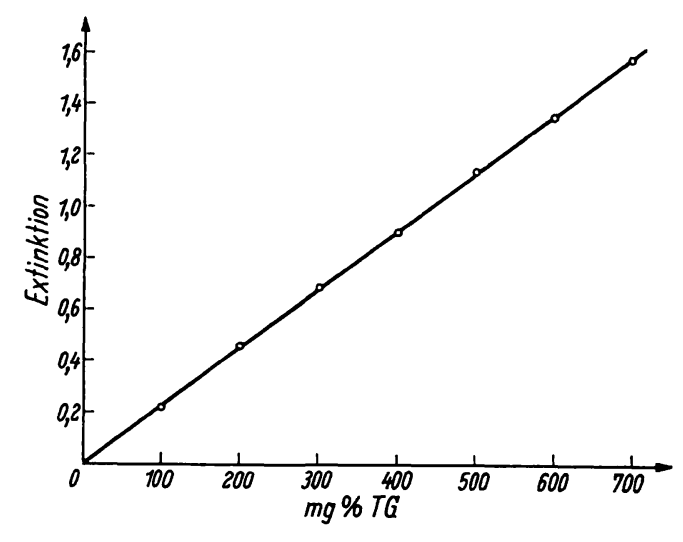

Abb. 2

Eichkurve für Photometer Leifo E; Filter $420,1 \mathrm{~cm}$ Schichtdicke, Faktor $F=445$

Der Leerwert wurde nach zwei Methoden bestimmt. Bei 50 Proben wurden vom Chloroformextrakt je $2 \mathrm{ml}$ in zwei Reagenzgläser pipettiert. Nach Abdampfen des Chloroforms wurde zum 1. Glas (Versuch) alkoholische Kalilauge, zum 2. Glas (Leerversuch) 96-proz. reiner Alkohol gegeben. Beide Proben wurden nach Vorschrift weiterverarbeitet. Die Extinktion des so erhaltenen Leerwertes stimmte mit dem Leerwert nach der Arbeitsvorschrift (ohne Chloroformextrakt) überein, so daß sich der Ansatz ohne Verseifung erübrigt.
Reproduzierbarkeit und Genauigkeit der Methode

Zur Errechnung des mittleren Fehlers wurden 100 Doppelbestimmungen durchgeführt. Er wurde wie folgt errechnet:

$$
\mathrm{F}_{\mathrm{m}}=\sqrt{\frac{\Sigma \Delta^{2}}{\mathrm{~N}}}
$$

$\mathrm{N}=$ Anzahl der Doppelbest.; $\Delta=$ Abweichung der Doppelbest.; Gefundener mittlerer Fehler $F_{m}=2,3$ $\mathrm{mg} \%$.

Ferner wurden zwei Seren steigende Mengen Triglyceride zugesetzt. Dazu wurden zu je $1 \mathrm{ml}$ Serum $1-5 \mathrm{ml}$ einer $50 \mathrm{mg} \%$ Standardlösung zugesetzt, die Chloroformlösung ad $20 \mathrm{ml}$ aufgefüllt, $4 \mathrm{~g}$ Kieselgel zugegeben und die Bestimmung wie beschrieben durchgeführt. Das Ergebnis zeigt Tabelle 1.

Tab. 1

Wiedergewinnung zugesetzter Triglyceride (Werte in $\mathrm{mg} \%$ )

\begin{tabular}{|c|c|c|c|c|c|c|c|}
\hline \multicolumn{2}{|c|}{$\begin{array}{c}\text { Serum } \\
\text { Eigengehalt }\end{array}$} & \multicolumn{2}{|c|}{ Zugesetzt } & \multicolumn{2}{|c|}{ Erhalten } & \multicolumn{2}{|c|}{ Wiedergefunden } \\
\hline $\mathbf{A}$ & $\mathbf{B}$ & A & B & A & B & A & B \\
\hline \multirow{5}{*}{107} & \multirow{5}{*}{213} & 50 & 50 & 156 & 265 & 49 & 52 \\
\hline & & 100 & 100 & 207 & 312 & 100 & 99 \\
\hline & & 150 & 150 & 259 & 364 & 152 & 151 \\
\hline & & 200 & 200 & 308 & 416 & 201 & 203 \\
\hline & & 250 & 250 & 356 & 463 & 249 & 250 \\
\hline
\end{tabular}

Normalwerte

Zur Bestimmung der Normalwerte wurden aus dem Krankengut solche Fälle untersucht, die nach der Diagnose keine unnormalen Lipidwerte erwarten ließen. Außerdem wurde zu jeder Triglyceridbestimmung eine Cholesterinbestimmung nach SCHÖNHEIMER und SPERRY (9) durchgeführt. Seren mit einem Cholesterinwert über $260 \mathrm{mg} \%$ wurden für die Berechnung der Normalwerte nicht berücksichtigt. Unter diesen Voraussetzungen ergaben sich aus 200 Analysen Normalwerte von $40-128 \mathrm{mg} \%$, im Mittel $86 \mathrm{mg} \%$.

Frau E. GrahL danke ich für die wertvolle technische Hilfe bei der Durchführung der Bestimmungen. Herrn Dr. F. FreTwurst danke ich für das fördernde Interesse, das er dieser Arbeit entgegenbrachte.

\section{Literatur}

1. van Hander, E. und D. B Zilversmit, J. Laborat. Clin. Med., S. Louis 50, 152 (1957). - 2. LAMBert, M. und A. C. NeIsh, Canad. J. Res., Sect. 28, 83 (1950). - 3 Menderson, D. und A. Antonis, J. Lipid Res. 2, 45 (1961). - 4. Eggstein, M. und F. KREUtz in: ZölLNER, N. und D. Eberhagen, Untersuchung und Bestimmung der Lipoide im Blut. Springer-Verlag,Ber lin-
Heidelberg-New York (1965). - 5. Hantzsch, A., Liebigs Ann. Chem. 215, 1 (1882). - 6. NAsH, T., Biochem. J. 55, 416 (1953). 7. Borgström, B., Acta physiol. scand. 25, 101 (1952). - 8. TrAppe. W., Biochem. Z. 305, 150 (1940). - 9 SchöNheIMER, R. und W. M. SpERRY, J. biol. Chemistry 106; 745 (1934); 110, 150 (1935).
Dr. rer. nat. F. Dunsbach Krankenhaus Nordwest Zentrallabor 6 Frankfurt/M 21 Steinbacher Hohl 2-26 